\title{
Grouping of experimental conditions as an approach to evaluate effects of extremely low-frequency magnetic fields on oxidative response in in vitro studies
}

\author{
Mats-Olof Mattsson* and Myrtill Simkó \\ Environmental Resources and Technologies, Department Health and Environment, AlT Austrian Institute of Technology, Tulln, Austria
}

\section{Edited by:}

Dariusz Leszczynski, University of

Helsinki, Finland

Reviewed by:

Rony Seger, Weizmann Institute of Science, Israel

Marko Markov, Research

International, USA

*Correspondence:

Mats-Olof Mattsson, Environmental

Resources and Technologies,

Department Health and Environment,

AlT Austrian Institute of Technology,

Konrad-Lorenz-Strasse 24, Tulln

A-3430, Austria

e-mail: mats-olof.mattsson@ait.ac
A large body of literature deals with biological effects of extremely low-frequency magnetic fields (ELF MFs) studied in vitro. Despite the multitude of studies, no coherent picture has evolved regarding the plausibility of effects at low-flux densities or regarding the interaction mechanisms. Here, we propose that ELF MF exposure in vitro causes changes in oxidative status as an early response. We tested this hypothesis by scrutinizing the literature and applying a grouping approach for analyzing relevant biological properties and exposure conditions. A total of 41 scientific original publications were analyzed for this purpose. The conclusion from the work is that ELF MF (modulated or unmodulated) consistently can influence the oxidative status, at or above $1 \mathrm{mT}$, in a broad range of cell types and independent of exposure duration. A response at lower flux densities is seen in certain studies, although not consistently. Further studies with stringent protocols for sham exposure, blinding, and statistical analysis as well as appropriate positive controls are needed to establish if true dose-relationships for effects on oxidative status exist.

Keywords: mammalian cells, immune-relevant cells, flux density, exposure duration, ROS

\section{INTRODUCTION}

Extremely low-frequency magnetic fields (ELF MFs; $1-300 \mathrm{~Hz}$ ) are widely present in the modern society. Such MFs originate primarily from distribution and usage of electricity and are typically found at higher magnetic flux densities in the vicinity of power lines and devices using strong electric currents. For decades, epidemiological as well as experimental studies have addressed possible health effects of exposure to these and also to higher frequency (electro)MF. Regarding chronic health effects, the International Agency for Research on Cancer (1) has classified low-frequency MF as a "possible carcinogen" (IARC class 2B). This classification is based on indirect evidence, i.e., epidemiological findings of increased risk for childhood leukemia in domestic settings where the MF-level is higher than the commonly found levels (daily averages exceeding $0.3-0.4 \mu \mathrm{T})(2,3)$. However, there is no supporting evidence for this classification from animal experiments. Furthermore, there are no mechanistic data that can provide an explanation for any effect on biological structures at the flux density levels that have been identified in the epidemiological studies.

It has been established that acute effects on excitable tissues (nerve and muscle) can occur at magnetic flux densities that are much higher than the ones associated with an increased risk for childhood leukemia (at millitesla levels compared to tenths of microtesla). Current exposure guidelines, such as those published by the international commission on non-ionizing protection [e.g., Ref. (4)], are set to protect against such established effects. Although the epidemiological findings of the association between MF exposure and childhood leukemia are indicating that chronic average exposures above $0.3-0.4 \mu \mathrm{T}$ are having an effect on disease development, there is no evidence for any causal relationships, and no other long-term effects have been established.

The scientific literature contains many experimental studies reporting various biological effects of exposure to ELF MF [see, e.g., comprehensive overviews in the opinions of SCENIHR (5, 6)]. The relevance for any disease outcome from these studies is unclear. Although these studies have been performed for decades, they have not provided with any convincing evidence for mechanistic explanations of any biological effect at low-flux density levels (at or below ICNIRP reference levels) and have not provided with consistent findings that are supporting epidemiological data.

The reported effects from in vitro studies include virtually all sorts of end points. This includes effects on DNA structure, gene expression, cell growth and survival, cellular metabolism, motility, protein functions, etc. It has to be noted, however, that despite the considerable number of studies with observed effects, studies not finding any effects are also very common. There is thus considerable inconsistency in the published literature. Unlike the situation in, e.g., chemical toxicology, in the case of observed effects, many studies have not addressed the issue of dose-response relationships. There is also a clear lack of systematic approaches to other important characteristics such as exposure duration.

Here, we focus on the status of oxidative responses, including free radical release, after MF exposure as an example of a biologically relevant endpoint. Free radicals, or as the term we use in the present paper, reactive oxygen species (ROS), are atoms or molecules that contain one or more unpaired electrons, which makes free radicals highly reactive, striving to form pairs to counteract the labile unpaired condition. Free radicals gain electrons from any available donor or donate an electron to a suitable acceptor, which 
in turn becomes modified into a secondary free radical. This chain reaction can cause biological damage leading to macromolecule damage such as DNA modifications or protein oxidation.

During aerobic conditions, free radicals are produced during and through normal metabolic processes. Key sources include electron transfer in the plasma membrane and cell respiration in the mitochondrial membrane. The production can proceed enzymatically or non-enzymatically. Shigenaga et al. (7) suggested that the mitochondria are the main source of the oxidative damage because free radicals such as superoxide can escape from the electron transport chain. About $3-10 \%$ of the oxygen turned over there is not fully processed, i.e., reduced. ROS from the mitochondria can enter the cytosol and react with other substances and thereby form new radicals. This triggers a chain reaction in which electrons change their owners, which can lead to DNA modification or enzyme disruption.

In order to counteract intracellular damage by free radicals, cells have antioxidant systems. These transform free electrons into a non-reactive form by proteins or enzymes. Antioxidants regulate oxidative reactions by inhibiting, delaying, or hampering the oxidation of the molecules (8). The intracellular enzymes that function as antioxidants are the backbone of this cellular defense system $(9,10)$. The key antioxidant enzymes are catalase (CAT), superoxide dismutase (SOD), and various peroxidases. In addition, non-enzymatic antioxidants can also neutralize radicals (e.g., vitamin $\mathrm{C}, \mathrm{E}$ or $\mathrm{A} / \beta$-carotene, glutathione, and melatonin) (8).

Free radicals have a series of important functions, such as serving in the immune defense. Leukocytes and macrophages execute their bactericidal effects by the release of ROS as a cellular defense mechanism against entering pathogens, thus, killing bacteria, viruses, and degenerated cells. At low concentrations, ROS can act as second messengers and activate signaling cascades, which in turn can lead to physiological responses such as gene expression, cell proliferation, and apoptosis [for reviews see Ref. (11, 12)]. However, immune-relevant cells use the reactive potential of ROS also to fulfill important physiological functions such as regulating the vascular tone and those cell functions controlled by oxygen concentration. Oxidative stress is the result of an imbalance between the intracellular ROS production and the cellular defense mechanisms. The balance between oxidants and antioxidants, the redox homeostasis, can be disrupted by an increase in free radicals or a reduction of antioxidative substances. Depending on the duration and strength of the imbalance, the redox regulation of the cell fulfills a compensatory function. When a constant production of free radicals is triggered by oxidative stress, the redox homeostasis becomes unbalanced and the cellular mechanisms are no longer capable of establishing the normal levels. This can not only persistently change signal transduction but also lead to changes on gene and protein levels and thus further promote oxidative conditions or processes. This includes virtually all complex molecules that can gain a single electron (DNA, proteins, lipids, and carbohydrates).

Despite that numerous investigations have shown the presence of a multitude of biological effects of ELF MF exposure, the first point of interaction between MF and cells, and the underlying molecular mechanisms, are still not clear. However, the release of ROS or other oxidative processes are often connected to the investigated effects. Therefore, we assume that oxidative processes triggered by MF play a key role within the effectiveness of MF $(13,14)$. Here, we focus on in vitro studies investigating the oxidative processes after exposure to low-frequency MF. Our hypothesis is that MF exposure consistently can trigger oxidative responses in cultured mammalian cells. Moreover, we apply a grouping approach to analyze relevant biological or exposure conditions for MF triggered oxidative processes.

We have asked a set of questions regarding (exposure) conditions and biological responses:

- Are responses related to the cell type used in the study?

- Are effects related to the magnetic flux density?

- Are the effects related to modulation of the MF signal?

- Are the responses related to exposure duration?

In addition, we have also evaluated certain quality criteria in the studies, such as whether or not true sham exposure conditions have been employed; if blinded protocols have been used; and if the appropriate positive controls have been included in the studies. Finally, we investigate the "effect size" of the response in the form of ROS production.

\section{APPROACH AND OUTCOMES}

We have identified (PubMed ${ }^{1}$ and EMF-Portal ${ }^{2}$ ) 41 published papers in the English language dealing with oxidative processes after ELF MF exposure of mammalian cells in vitro. Many of these studies have already been extensively reviewed $(5,6,13-$ 15). Therefore, our goal is to evaluate these studies by identifying and using a "grouping" tool to classify relevant conditions, such as cell type, and/or exposure conditions, for cellular response after MF exposure and not to perform a comprehensive review. We are aware of the limited number of relevant studies and also about the inadequate quality of some of the investigations. Consequently, some additional studies have not been included in this article since those studies have not matched our inclusion criteria, which include the possibility to follow the exposure and experimental approach. We were especially excluding studies where exposure or other experimental conditions were inappropriate and/or unsatisfactory described. The level of criteria is admittedly low, but was accepted on practical grounds, otherwise only few publications would have been taken into account.

First of all, we have considered "positive" and "negative" findings among the publications. A "positive" study refers to a study where an effect of MF is shown, with valid methods described in enough detail to constitute evidence supporting the study hypothesis. If a well-conducted and appropriately reported study shows no clear effect despite proper methods and statistical power, its results provide evidence against the study hypothesis (but support the null hypothesis), and the study is considered "negative" (Table 1).

Here, we consider oxidative response as the first "grouping" of biological endpoints. All positive findings (independent of

\footnotetext{
${ }^{1}$ www.ncbi.nlm.nih.gov

${ }^{2}$ www.emf-portal.de
} 
Table 1 | Summary of identified relevant studies

\begin{tabular}{|c|c|c|c|c|c|c|}
\hline \multicolumn{4}{|c|}{ Cells } & \multirow{2}{*}{$\begin{array}{l}\begin{array}{l}\text { Exposure } \\
\text { conditions }\end{array} \\
20-5000 \mathrm{~Hz} \\
5 \mu \mathrm{T} \\
30 \mathrm{~min}\end{array}$} & \multirow{2}{*}{$\begin{array}{c}\begin{array}{c}\text { Oxidative } \\
\text { response }^{\text {a }}\end{array} \\
\text { No }\end{array}$} & \multirow{2}{*}{$\begin{array}{c}\text { Reference } \\
(16)\end{array}$} \\
\hline $\begin{array}{l}\text { Human peripheral blood } \\
\text { mononuclear cells }\end{array}$ & Mononuclear cells & Primary & Immune relevant & & & \\
\hline $\begin{array}{l}\text { Human peripheral blood } \\
\text { mononuclear cells }\end{array}$ & Mononuclear cells & Primary & Immune relevant & $\begin{array}{l}50 \text { or } 60 \mathrm{~Hz} \\
2,20,100,500 \mu \mathrm{T} \\
6 \mathrm{~h}\end{array}$ & No & (17) \\
\hline $\begin{array}{l}\text { MCF10A human breast } \\
\text { epithelial cells }\end{array}$ & Breast epithelial cells & Cell line & Other cell line & $\begin{array}{l}60 \mathrm{~Hz} \\
1 \mathrm{mT} \\
4 \mathrm{~h}\end{array}$ & No & (18) \\
\hline Murine L929 fibroblasts & Fibroblasts & Cell line & Other cell line & $\begin{array}{l}50 \mathrm{~Hz} \\
100 \text { or } 300 \mu \mathrm{T} \\
1 \text { or } 24 \mathrm{~h}\end{array}$ & No & (19) \\
\hline Rabbit red blood cells & Red blood cells & Primary & Other primary cells & $\begin{array}{l}50 \mathrm{~Hz} \\
0.2,0.5 \mathrm{mT} \\
45,90 \mathrm{~min}\end{array}$ & No & (21) \\
\hline $\begin{array}{l}\text { THP-1 cells (human } \\
\text { monocytic leukemia cell } \\
\text { line) }\end{array}$ & Leukemia & Cell line & Immune relevant & $\begin{array}{l}50 \mathrm{~Hz} \\
1 \mathrm{mT} \\
4 \mathrm{~h}\end{array}$ & Yes & (22) \\
\hline K562 cells & Myelogenous leukemia & Cell line & Immune relevant & $\begin{array}{l}50 \mathrm{~Hz} \\
1 \mathrm{mT} \\
3 \mathrm{~h}\end{array}$ & Yes & (23) \\
\hline $\begin{array}{l}\text { Human mono Mac } 6 \text { cells } \\
\text { Human umbilical cord } \\
\text { blood-derived monocytes }\end{array}$ & $\begin{array}{l}\text { Monocytic leukemia } \\
\text { Monocytes }\end{array}$ & $\begin{array}{l}\text { Cell line } \\
\text { Primary }\end{array}$ & Immune relevant & $\begin{array}{l}50 \mathrm{~Hz} \\
1 \mathrm{mT} \\
45 \mathrm{~min}\end{array}$ & Yes & (26) \\
\hline K562 cells & Myelogenous leukemia & Cell line & Immune relevant & $\begin{array}{l}50 \mathrm{~Hz} \\
0.025-0.10 \mathrm{mT} \\
1 \mathrm{~h}\end{array}$ & Yes & $(27)$ \\
\hline THP-1 & Monocytic cells & Cell line & Immune relevant & $\begin{array}{l}50 \mathrm{~Hz} \\
1 \mathrm{mT} \\
6,24 \mathrm{~h}\end{array}$ & Yes & (28) \\
\hline $\begin{array}{l}\text { Primary mouse } \\
\text { macrophages }\end{array}$ & Macrophages & Primary & Immune relevant & $\begin{array}{l}50 \mathrm{~Hz} \\
0.05-1.0 \mathrm{mT} \\
45 \mathrm{~min}-48 \mathrm{~h}\end{array}$ & Yes & (29) \\
\hline $\begin{array}{l}\text { Mouse macrophages from } \\
\text { isolated bone marrow } \\
\text { precursor cells }\end{array}$ & Macrophages & Primary & Immune relevant & $\begin{array}{l}50 \mathrm{~Hz} \\
1 \mathrm{mT} \\
5 \mathrm{~min}-24 \mathrm{~h}\end{array}$ & Yes & (30) \\
\hline
\end{tabular}


Table 1 | Continued

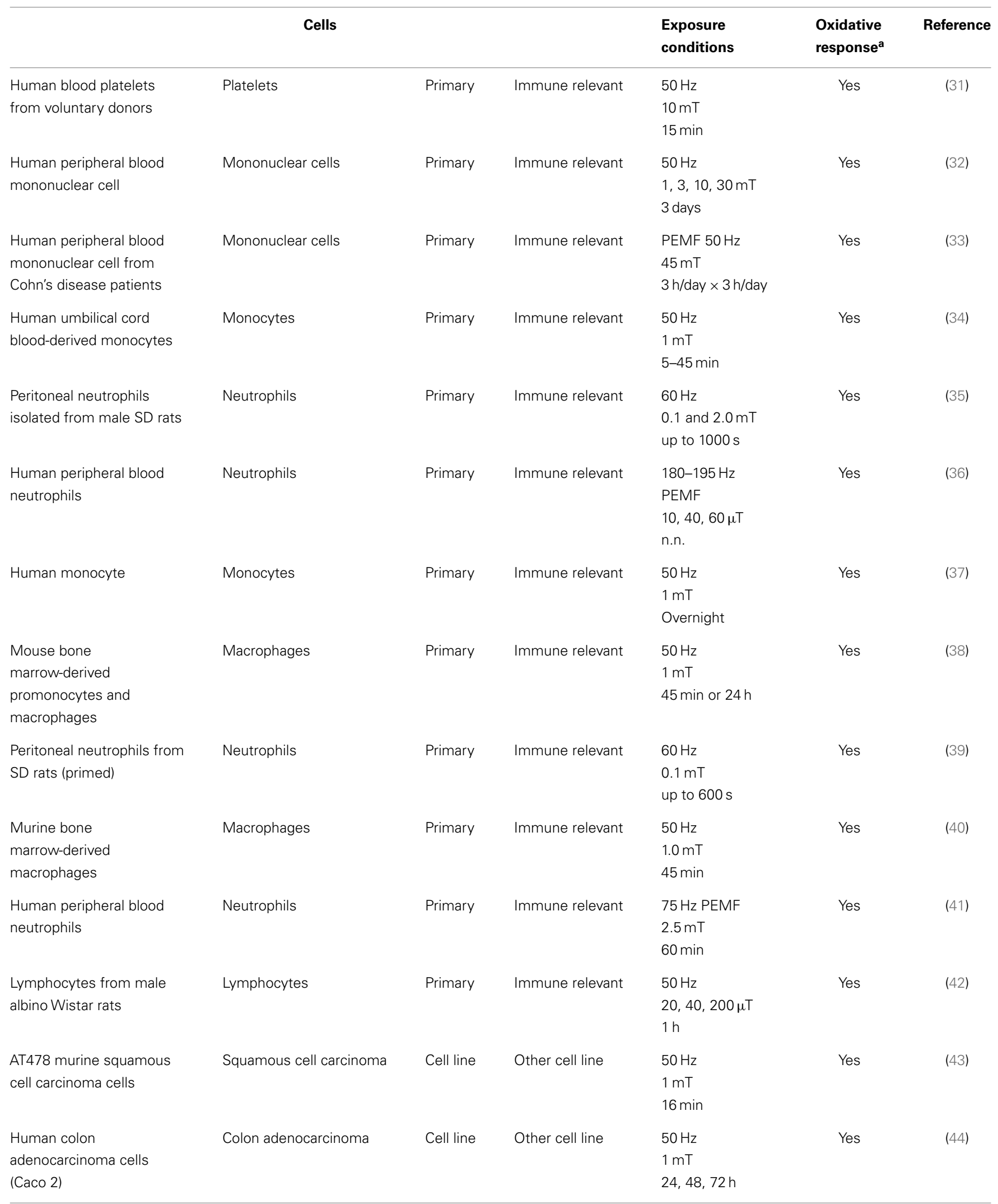




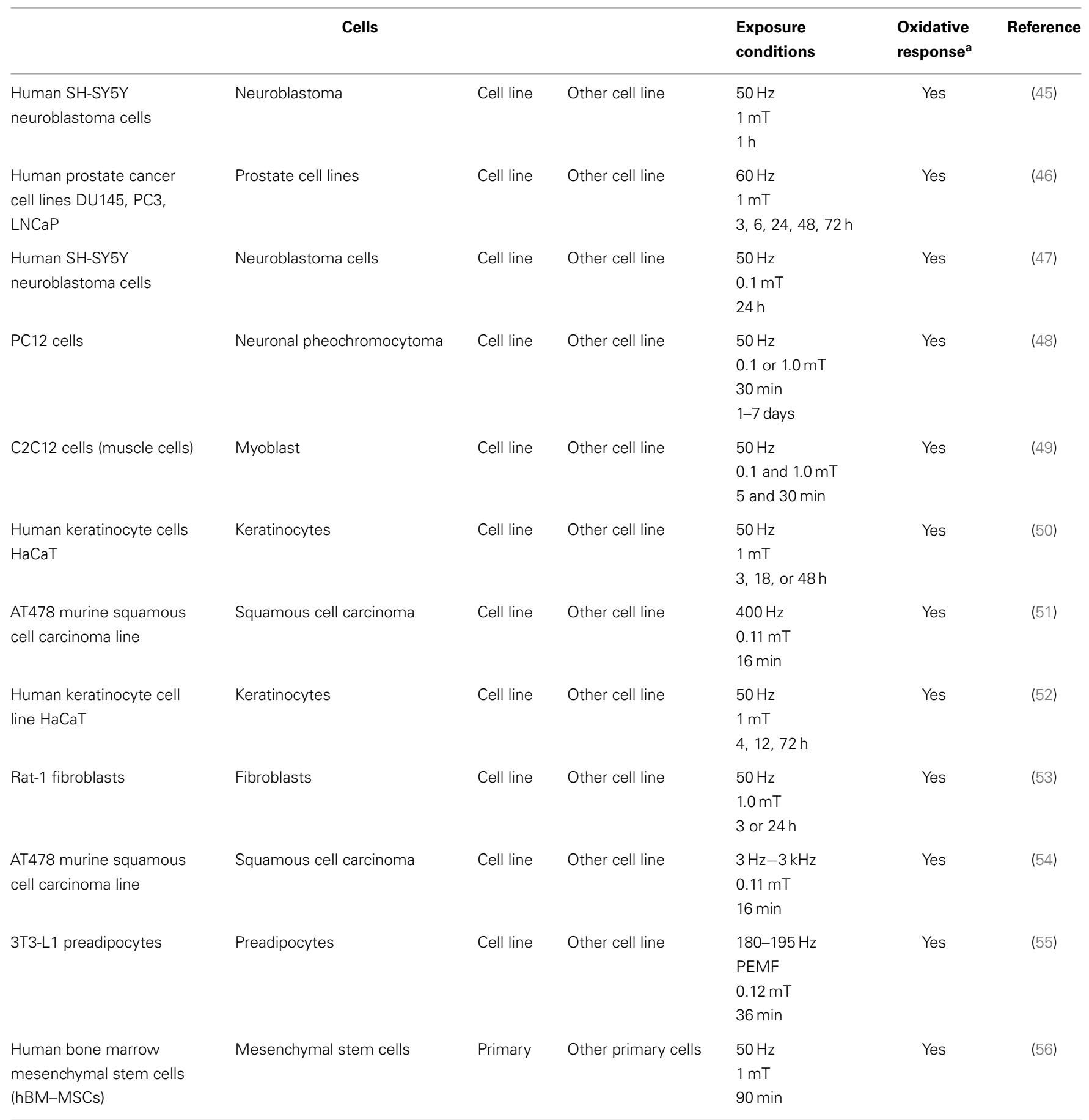

${ }^{a}$ Yes, positive finding; no, negative finding.

whether the response is an increase or a decrease compared to the control situation) were taken into account after exposure to MF, where any kind of oxidative response related data has been detected. These include changes not only in ROS production, in expression/activity of antioxidants, intermediate-release such as inflammation related cytokines, nitrogen oxides, but also in relevant protein expressions and/or phosphorylation.
Further on, the number of different cell types was identified and compiled into the following groups: immune-relevant primary cells, immune-relevant cell lines, other primary cells, and other cell lines (Table 1; where a summary of identified relevant studies is presented). Within the two cell line groups, cancer or non-cancer cells were sub-grouped. However, data are not shown since we could not identify any trend. 
The main and most relevant exposure conditions were identified as the frequency of the applied field, frequency modulations including pulsed-electromagnetic fields (PEMF), the flux density, and the exposure duration. These conditions were sub-grouped into larger units to identify relevant conditions for positive or negative findings.

Within these 41 publications, 42 different "datasets" have been identified utilizing 29 different cell types (Figure 1). The majority of the studies, namely 36 , reported positive findings regarding oxidative responses after MF exposure (corresponding to a positive finding ratio of 0.86 ). Some investigators used different cell types for comparative analysis. As shown in Figure 1, there is no clear trend indicating a cell type dependent MF effect. However, by pooling immune-relevant cells (independent if primary cells or cell line), 22 positive findings were detected (out of 24). Using non-immune-relevant cells or cell lines, out of 18 investigations, 14 showed positive findings.

By analyzing the employed frequencies, we considered nonmodulated sine wave ELF MF as a "group" (almost all studies were at $50 / 60 \mathrm{~Hz}$ ) and modulated MF as a second group where PEMF or other frequency modulations or waveforms were used. Only few studies investigated the effect of modulated MF. Of these, seven studies showed positive findings and one no effect. The majority of the studies, namely 34 , employed non-modulated MF. Among those, 29 investigations detected oxidative response, and 5 detected no effects (Figure 2). Because of the imbalance between the number of studies of "modulated" and "non-modulated" (34 vs. 8) frequencies, it is not possible to detect an association or trend whether the frequency parameter is relevant for a biological response.
To analyze the flux density dependency of the performed studies, we grouped the employed field strength as follows: $\leq 0.1$, $0.1-0.99$, and $\geq 1 \mathrm{mT}$. Some investigators used several different flux densities. Out of 68 investigations, 51 detected positive findings: 30 used $\geq 1 \mathrm{mT}, 9$ used $0.1-0.99 \mathrm{mT}$, and at 12 times $\leq 0.1 \mathrm{mT}$ was employed. No effects were detected in a total of 17 investigations ( 2 in $\geq 1 \mathrm{mT}, 8$ in $0.1-0.99 \mathrm{mT}$, and 7 in the group of $\leq 0.1 \mathrm{mT}$ ). It seems that below $0.1 \mathrm{mT}$ and around $1 \mathrm{mT}$ oxidative response appears in the majority of the used immune-relevant primary cells (23) (Figure 3). Based on this data, it is plausible to suggest that $\geq 1 \mathrm{mT}$ induces oxidative responses (30) with a ratio of 0.94 . At the other flux density levels, this distinct picture does not appear. The ratio for positive findings is in the group of $<0.1 \mathrm{mT} 0.63$ and in the group of $0.1-0.99 \mathrm{mT} 0.53$.

It has been discussed that the exposure duration is another important condition for bioeffects. To identify if this is the case, we introduced three groups of exposure durations: $\leq 60 \mathrm{~min},>1 \mathrm{~h}$ up to $24 \mathrm{~h}$, and more than 1 day. Out of 69 investigations, oxidative response was shown in 49 studies. It seems that the exposure duration is not relevant for the biological response (Figure 4). Short exposure (up to $60 \mathrm{~min}$ ) resulted in 23 papers in an effect, whereas no effects were reported in 7 papers (a ratio of 0.77 ). MF exposure up to $24 \mathrm{~h}$ resulted in 18 positive cases and in 9 negative cases (ratio 0.67), whereas after exposure up to day/s, in 8 positive papers and in 4 negative results were reported (ratio 0.67 ).

To investigate the quality of the studies, where proper sham control conditions, statistical analysis, and other criteria such as blinded protocols were not taken into account (since this would have reduced the number of relevant studies very dramatically), we analyzed how often positive controls were applied as a quality

\section{Cell types}

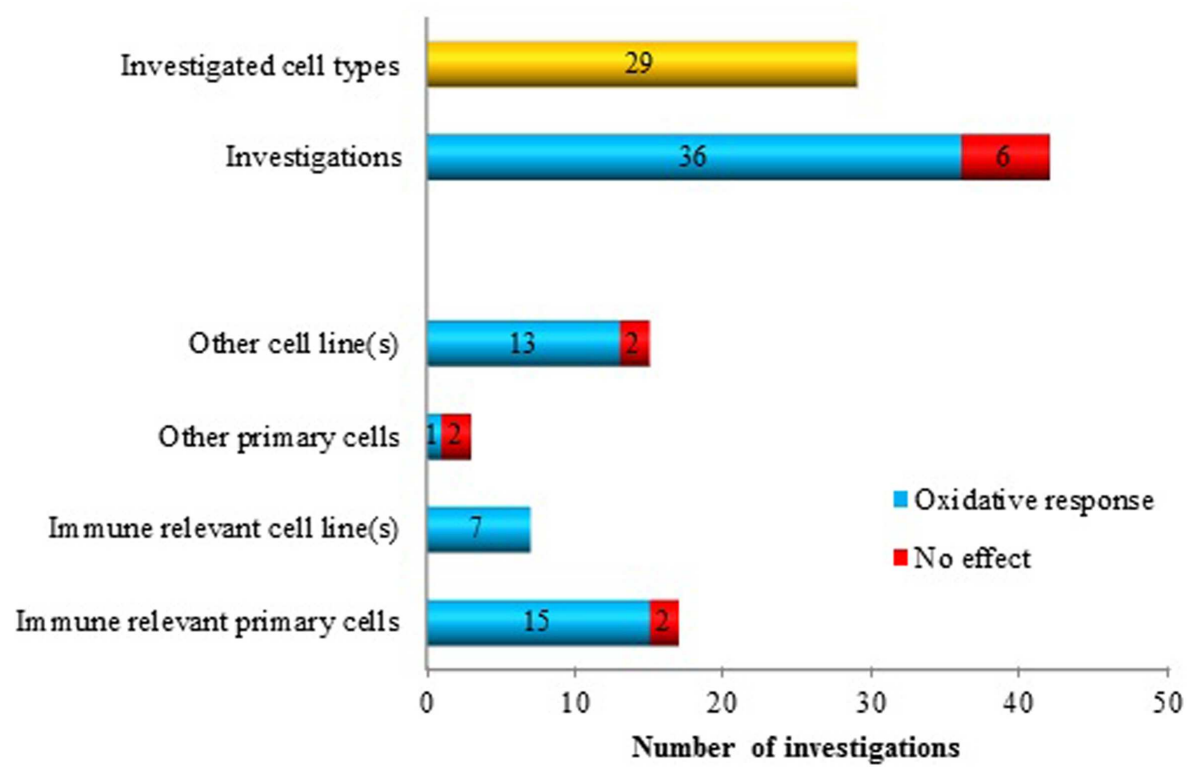

FIGURE 1 | Oxidative response as a positive or negative finding after exposure to ELF MF in different cell types. 


\section{Frequency/Modulation}

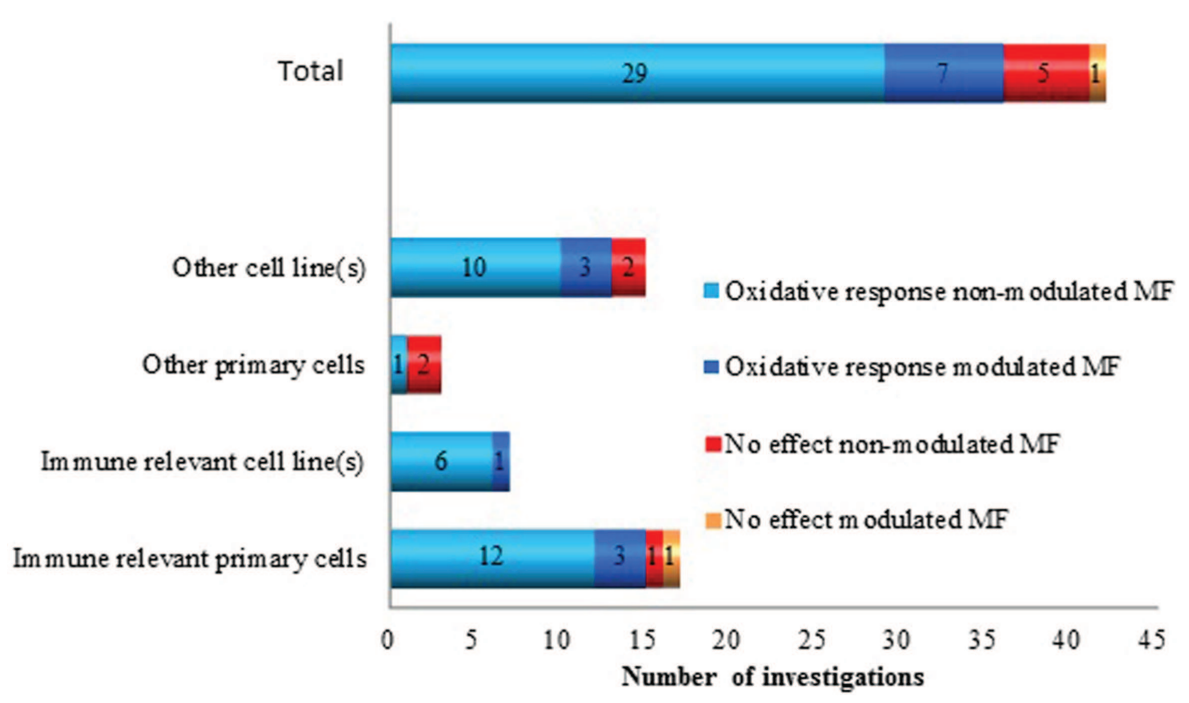

FIGURE 2 | Oxidative response as a positive or negative finding after exposure to non-modulated or modulated ELF MF in different cell types

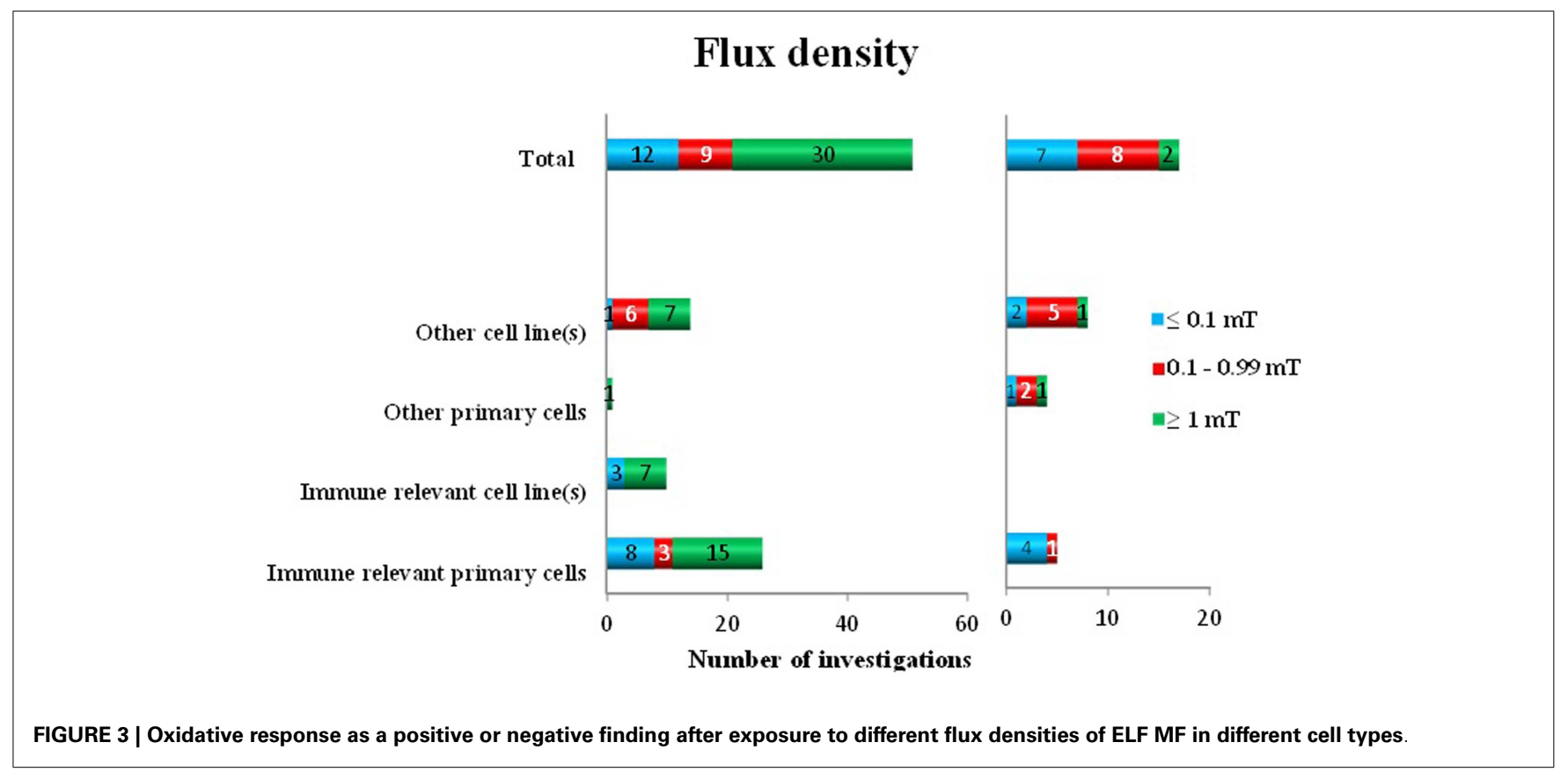

control measure of the study. Of the positive findings, 21 investigations used positive controls. Many of these were investigating co-exposure effects (62\%) (Figure 5). Among the negative findings, five papers reported the use of positive controls, all in studies of co-exposure effects.

A good measure of the "effect size" is the most common endpoint among the investigated oxidative responses, namely, superoxide radical anion and/or ROS production. However, the effect size is not amenable for grouping purposes, since it is only one parameter. In 18 publications, superoxide radical anion and/or ROS production were reported positive effects. Of these, 17 showed a change between 30 and $90 \%$ and one publication was not reporting the size of the effect. Several investigators analyzed this effect after more than one exposure/co-exposure condition. In total, 20 observations showed an increase (up to 90\%) and 4 a decrease (20-40\%) and 1 showed no effect due to a certain condition in superoxide radical anion and/or ROS release. However, out of these 25 "datasets," only four investigations reported a change 


\section{Exposure duration}

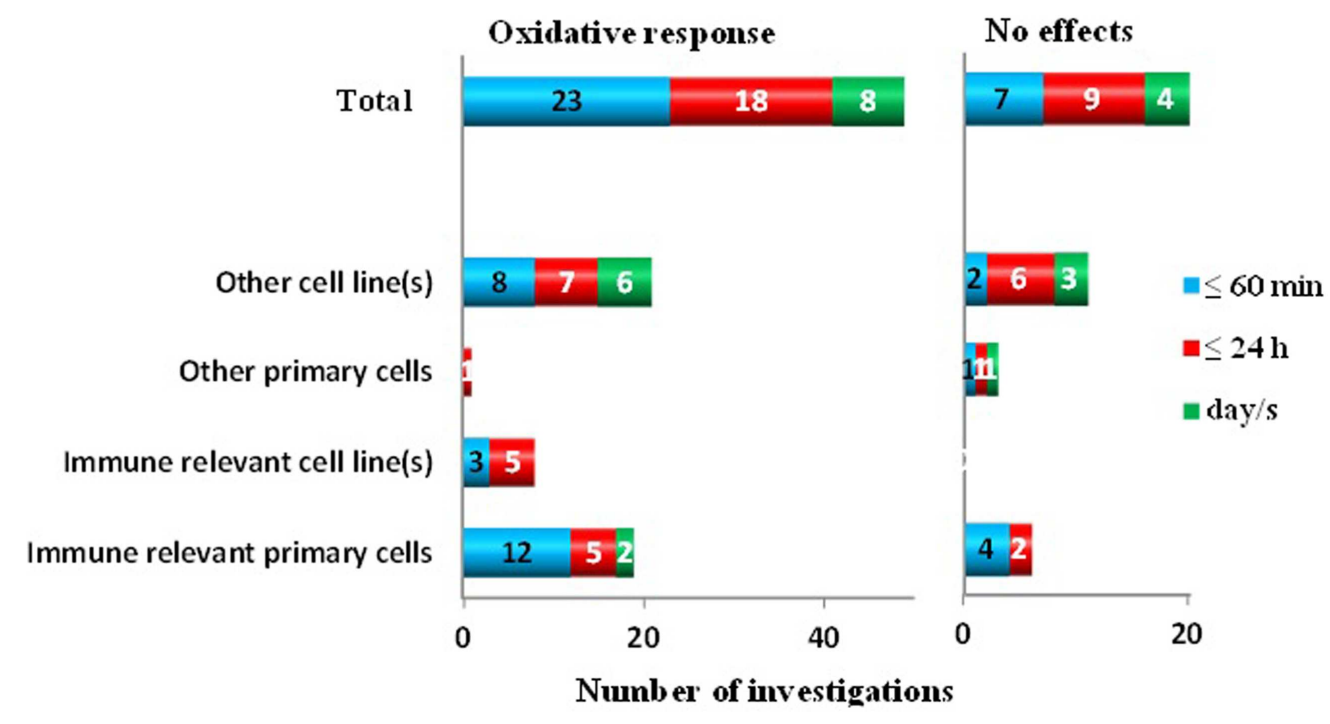

FIGURE 4 | Oxidative response as a positive or negative finding after different exposure durations to ELF MF in different cell types.

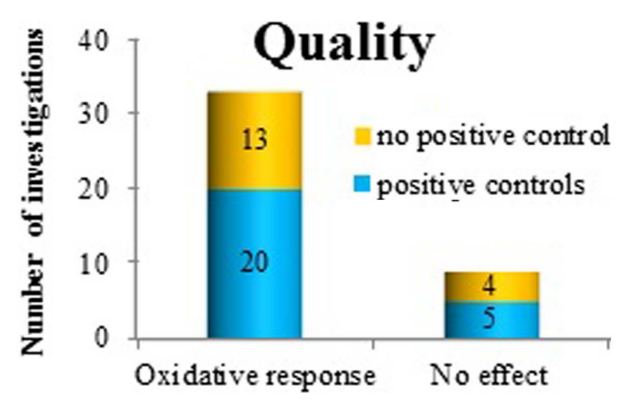

FIGURE 5 |The use of positive controls in investigating oxidative response as a positive or negative finding after exposure to ELF MF.

between 50 and 90\%. All other data showed a change in superoxide radical anion and/or ROS production at a level of $30-50 \%$ (Figure 6).

In summary, the majority of the reported studies were showing an oxidative response after MF exposure. However, it seems that none of the presented groups are decisive for the induction of oxidative response after exposure to MF.

\section{DISCUSSION}

Health effects research regarding ELF MF has to a large degree been driven by epidemiological findings where certain correlations between long-term exposures and chronic diseases have been found. The most apparent association is the increased risk for childhood leukemia in the presence of elevated domestic exposure levels (1). However, this is an example of a correlation between MF and a disease outcome. There are no experimental findings that can

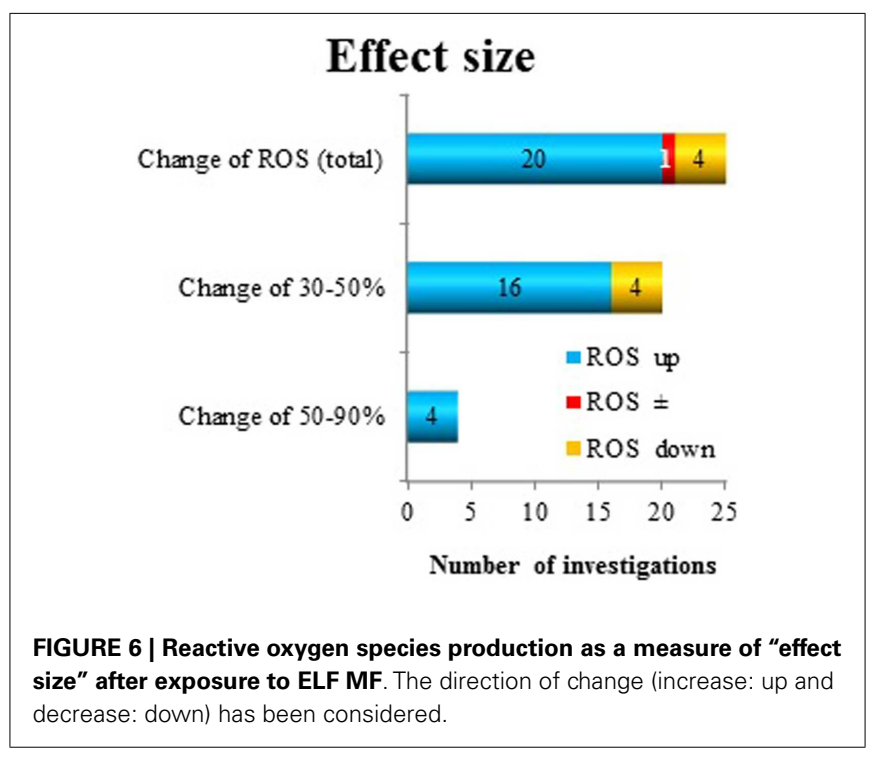

provide a mechanistic explanation for such an outcome. This can be interpreted in two ways: (1) there is no causative association between long-term low-level MF exposure and chronic diseases such as cancer; or (2) the systematic experimental studies that can provide a mechanistic explanation have not been performed.

One of the biological end points that have been frequently investigated is the oxidative status of the biological system. This is due both to that it is reasonable to assume that early responses to external stressors involve changes in oxidative homeostasis, discussed in several recent reviews (57-60) and also that possible lasting effects on the oxidative balance could influence a number 
of cellular processes in such a way that disease conditions can develop (61-64).

We have published some studies in this field (see Table 1 for pertinent references), and also suggested that an early response to ELF MF is effects on radical homeostasis [e.g., Ref. $(13,14)]$. Based on this, we formulated our present hypothesis, viz. that ELF MF exposure consistently triggers oxidative responses in cultured mammalian cells. Taking the complexity of both the exposure situation (with various frequencies, waveforms, modulations, flux densities, presence of other MF, duration, exposure periodization, etc.) and the multitude of biological processes that are more or less relevant endpoints into consideration, it is clear that it is not necessarily easy to test this hypothesis. Therefore, we have decided to use a simple grouping approach to systematically order the available data. Grouping as a tool to make order in, e.g., chemical toxicology situations is well established (65) but has to our knowledge not been used in the field of bioeffects of MF. Nevertheless, we have identified a clear need to use a systematic approach to analyze the published data on the subject of MF exposure and oxidative responses.

What then, has our test of the hypothesis revealed? The outcome of the present analysis, based on relevant available data, is that the hypothesis cannot be rejected. This is due to that the majority of investigated studies showed positive effects, over a broad range of cell types, exposure durations, and flux densities.

What is the support for the statement that the hypothesis is still surviving, but needs to be tested with more precise and distinct approaches? Regarding cell type specific responses, there is no support from the available data to say that specific cell types display more or less sensitivity to the exposure (Figure 1). Rather, positive effects were seen in all the cell type categories that we identified. A caveat is that immune-relevant cells (primary cells as well as cell lines) have been the most frequently used models. This is reasonable, since immune cells employ rapid oxidative responses in their activities. However, since so few studies (i.e., three) of the category "other primary cells" have been studied, further investigations of these cell types would be needed to develop this point further.

When analyzing the responses to various flux densities, several observations are obvious. Most investigations used exposure levels of $1 \mathrm{mT}$ or higher, which almost completely resulted in an oxidative responses, in all investigated cell types. Only $6 \%$ of the investigations displayed no effects. Regarding exposures below $1 \mathrm{mT}$, the outcome is mixed. There are somewhat more positive than negative studies in both lower exposure groups, although the negative findings are well represented as well. Interestingly, there are several positive studies also at or below $0.10 \mathrm{mT}$. The number of independent studies employing flux densities below $0.10 \mathrm{mT}$ is low, however. Virtually no studies have employed flux densities comparable to environmental levels (single microtesla or lower). Unfortunately, there are very few of the studies that have been performing real dose-response investigations, with several flux density levels. A conclusion regarding a possible threshold effect is also not possible to draw, based on these data. The possibility of a real dose-response pattern does exist, which easily could be addressed in future studies.

Neither the grouping of data based on frequency or modulation (Figure 3) nor exposure duration (Figure 4) showed any support for that very specific conditions are decisive for positive effects. Although most of the studies have been performed at $50 / 60 \mathrm{~Hz}$, also other frequencies and pulsed MF were represented in both positive and negative findings. A similar pattern is also present when analyzing the importance of exposure duration. Short(minutes) to long-exposure times (days) were all used in the studies where oxidative responses were noted.

The effect size of the responses in the form of ROS levels were between 30 and $90 \%$ change from the control conditions (Figure 6). These changes were mostly increases, although also decreased levels due to exposure were found in a few studies (4 out of 24 studies where ROS responses were seen). Most changes were in the interval $30-50 \%$. This level of change must be considered modest. Various appropriate positive (chemical) controls have been used in some of the studies. These compounds include $\mathrm{H}_{2} \mathrm{O}_{2}$, the phorbol ester TPA, the bacterial endotoxin LPS, and the cytostatic drug cisplatin. The increases in ROS levels due to these chemicals varied from around $40 \%$ increase up to several 10 -fold increases. The latter large increases correspond to an "oxidative burst" from the cells. This is a recognized characteristic of certain immune cells (57) and has never been seen after MF exposure (13, 14). Whether the small changes caused by MF exposure would have any biological significance is unknown. However, induction of ROS release at lower levels has recently been connected to disease development (61-64).

Regrettably, many studies did not include positive controls (see Figure 5) at all. As many as $40-50 \%$ of the studies (both those with and without any effect), lacked this crucial quality control. Obviously, this reduces the usefulness and the credibility of the findings, irrespective of whether they are positive or negative. We also looked for two other study quality markers, i.e., blinded protocols and proper sham exposure conditions. Only a couple of papers were employing both these routines.

Taking the quality criteria together, they weaken the conclusions that can be drawn from these studies. One needs also to keep in mind that the total number of studies that we investigated is relatively few. We furthermore do not know to what extent additional investigations have been unpublished, due to negative findings. Such a publication bias has been documented elsewhere when analyzing EMF biological effects (66). Taking everything into account, our interpretation is that there is evidence supporting that ELF MF cause oxidative responses in mammalian cells, most clearly at higher flux densities ( $1 \mathrm{mT}$ or higher).

\section{CONCLUSION}

Available evidence suggests that ELF MF (modulated/unmodulated) has an effect on oxidative status parameters, in both directions. The strongest association between MF exposure and effects occur at or above $1 \mathrm{mT}$, although effects are noted at or below $0.10 \mathrm{mT}$. Effects are not dependent on cell type or on exposure duration. Furthermore, the effects are modest in comparison with the responses to positive controls.

\section{AUTHOR CONTRIBUTIONS}

Both authors have contributed to all parts in the writing process, have approved the final version of the manuscript, and are both fully responsible for the content of the work. 


\section{REFERENCES}

1. IARC. Non-ionizing radiation, Part 1: static and extremely low-frequency (ELF) electric and magnetic fields. IARC Monogr Eval Carcinog Risks Hum (2002) 80:1-395.

2. Ahlbom A, Day N, Feychting M, Roman E, Skinner J, Dockerty J, et al. A pooled analysis of magnetic fields and childhood leukaemia. Br J Cancer (2000) 83(5):692-8. doi:10.1054/bjoc.2000.1376

3. Greenland S, Sheppard AR, Kaune WT, Poole C, Kelsh MA. A pooled analysis of magnetic fields, wire codes, and childhood leukemia. Childhood LeukemiaEMF Study Group. Epidemiology (2000) 11(6):624-34. doi:10.1097/00001648200011000-00003

4. ICNIRP. Guidelines for limiting exposure to time-varying electric and magnetic fields (1 Hz to $100 \mathrm{kHz}$ ). Health Phys (2010) 99(6):818-36. doi:10.1097/HP. $0 \mathrm{~b} 013 \mathrm{e} 3181 \mathrm{f} 06 \mathrm{c} 86$

5. SCENIHR. Health Effects of Exposure to EMF. (2009). Available from: http://ec.europa.eu/health/archive/ph_risk/committees/04_scenihr/docs/ scenihr_o_022.pdf

6. SCENIHR. Possible effects of Electromagnetic Fields (EMF) on Human Health. (2007). Available from: http://ec.europa.eu/health/archive/ph_risk/committees/ 04_scenihr/docs/scenihr_o_007.pdf

7. Shigenaga MK, Hagen TM, Ames BN. Oxidative damage and mitochondrial decay in aging. Proc Natl Acad Sci U S A (1994) 91(23):10771-8. doi:10.1073/ pnas.91.23.10771

8. Sies H. Oxidative stress: oxidants and antioxidants. Exp Physiol (1997) 82(2):291-5.

9. Dreher D, Jornot L, Junod AF. Effects of hypoxanthine-xanthine oxidase on $\mathrm{Ca} 2+$ stores and protein synthesis in human endothelial cells. Circ Res (1995) 76(3):388-95. doi:10.1161/01.RES.76.3.388

10. Dreher D, Junod AF. Differential effects of superoxide, hydrogen peroxide, and hydroxyl radical on intracellular calcium in human endothelial cells. J Cell Physiol (1995) 162(1):147-53. doi:10.1002/jcp.1041620118

11. Allen RG, Tresini M. Oxidative stress and gene regulation. Free Radic Biol Med (2000) 28(3):463-99. doi:10.1016/S0891-5849(99)00242-7

12. Brookes PS, Levonen AL, Shiva S, Sarti P, Darley-Usmar VM. Mitochondria: regulators of signal transduction by reactive oxygen and nitrogen species. Free Radic Biol Med (2002) 33(6):755-64. doi:10.1016/S0891-5849(02)00901-2

13. Simkó M. Cell type specific redox status is responsible for diverse electromagnetic field effects. Curr Med Chem (2007) 14(10):1141-52. doi:10.2174/ 092986707780362835

14. Simkó M, Mattsson MO. Extremely low frequency electromagnetic fields as effectors of cellular responses in vitro: possible immune cell activation. J Cell Biochem (2004) 93(1):83-92. doi:10.1002/jcb.20198

15. Mattsson MO, Simko M. Is there a relation between extremely low frequency magnetic field exposure, inflammation and neurodegenerative diseases? A review of in vivo and in vitro experimental evidence. Toxicology (2012) 301(13):1-12. doi:10.1016/j.tox.2012.06.011

16. de Kleijn S, Bouwens M, Verburg-van Kemenade BM, Cuppen JJ, Ferwerda G, Hermans PW. Extremely low frequency electromagnetic field exposure does not modulate toll-like receptor signaling in human peripheral blood mononuclear cells. Cytokine (2011) 54(1):43-50. doi:10.1016/j.cyto.2010.12.016

17. Ikeda K, Shinmura Y, Mizoe H, Yoshizawa H, Yoshida A, Kanao S, et al. No effects of extremely low frequency magnetic fields found on cytotoxic activities and cytokine production of human peripheral blood mononuclear cells in vitro. Bioelectromagnetics (2003) 24(1):21-31. doi:10.1002/bem.10062

18. Hong MN, Han NK, Lee HC, Ko YK, Chi SG, Lee YS, et al. Extremely low frequency magnetic fields do not elicit oxidative stress in MCF10A cells. J Radiat Res (2012) 53(1):79-86. doi:10.1269/jrr.11049

19. Markkanen A, Naarala J, Juutilainen JA. Study on the effects of $50 \mathrm{~Hz}$ magnetic fields on UV-induced radical reactions in murine fibroblasts. J Radiat Res (2010) 51(5):609-13. doi:10.1269/jrr.10038

20. Di Loreto S, Falone S, Caracciolo V, Sebastiani P, D’Alessandro A, Mirabilio A, et al. Fifty hertz extremely low-frequency magnetic field exposure elicits redox and trophic response in rat-cortical neurons. J Cell Physiol (2009) 219(2):334-43. doi:10.1002/jcp.21674

21. Fiorani M, Biagiarelli B, Vetrano F, Guidi G, Dacha M, Stocchi V. In vitro effects of $50 \mathrm{~Hz}$ magnetic fields on oxidatively damaged rabbit red blood cells. Bioelectromagnetics (1997) 18(2):125-31. doi:10.1002/(SICI)1521-186X(1997)18: $2<125:$ AID-BEM5>3.3.CO;2-H
22. Akan Z, Aksu B, Tulunay A, Bilsel S, Inhan-Garip A. Extremely lowfrequency electromagnetic fields affect the immune response of monocytederived macrophages to pathogens. Bioelectromagnetics (2010) 31(8):603-12. doi:10.1002/bem.20607

23. Garip AI, Akan Z. Effect of ELF-EMF on number of apoptotic cells; correlation with reactive oxygen species and HSP. Acta Biol Hung (2010) 61(2):158-67. doi:10.1556/ABiol.61.2010.2.4

24. Inhan-Garip A, Akan Z, Sule O, Isil IT, Kalkan T. Differentiation of K562 cells under ELF-EMF applied at different time courses. Electromagn Biol Med (2010) 29(3):122-30. doi:10.3109/15368378.2010.502451

25. Lin HY, Lin YJ. In vitro effects of low frequency electromagnetic fields on osteoblast proliferation and maturation in an inflammatory environment. Bioelectromagnetics (2011) 32(7):552-60. doi:10.1002/bem.20668

26. Lupke M, Rollwitz J, Simkó M. Cell activating capacity of $50 \mathrm{~Hz}$ magnetic fields to release reactive oxygen intermediates in human umbilical cord bloodderived monocytes and in Mono Mac 6 cells. Free Radic Res (2004) 38(9):985-93. doi:10.1080/10715760400000968

27. Mannerling AC, Simkó M, Mild KH, Mattsson MO. Effects of 50-Hz magnetic field exposure on superoxide radical anion formation and HSP70 induction in human K562 cells. Radiat Environ Biophys (2010) 49(4):731-41. doi:10.1007/s00411-010-0306-0

28. Patruno A, Tabrez S, Amerio P, Pesce M, Vianale G, Franceschelli S, et al. Kinetic study on the effects of extremely low frequency electromagnetic field on catalase, cytochrome P450 and inducible nitric oxide synthase in human $\mathrm{HaCaT}$ and THP-1 cell lines. CNS Neurol Disord Drug Targets (2011) 10(8):936-44. doi:10.2174/187152711799219325

29. Frahm J, Lantow M, Lupke M, Weiss DG, Simkó M. Alteration in cellular functions in mouse macrophages after exposure to $50 \mathrm{~Hz}$ magnetic fields. J Cell Biochem (2006) 99(1):168-77. doi:10.1002/jcb.20920

30. Frahm J, Mattsson MO, Simkó M. Exposure to ELF magnetic fields modulate redox related protein expression in mouse macrophages. Toxicol Lett (2010) 192(3):330-6. doi:10.1016/j.toxlet.2009.11.010

31. Henrykowska G, Jankowski W, Pacholski K, Lewicka M, Smigielski J, Dziedziczak-Buczynska M, et al. The effect of $50 \mathrm{hz}$ magnetic field of different shape on oxygen metabolism in blood platelets: in vitro studies. Int J Occup Med Environ Health (2009) 22(3):269-76. doi:10.2478/v10001-009-0019-2

32. Jonai H, Villanueva MB, Yasuda A. Cytokine profile of human peripheral blood mononuclear cells exposed to $50 \mathrm{~Hz}$ EMF. Ind Health (1996) 34(4):359-68. doi:10.2486/indhealth.34.359

33. Kaszuba-Zwoinska J, Ciecko-Michalska I, Madroszkiewicz D, Mach T, Slodowska-Hajduk Z, Rokita E, et al. Magnetic field anti-inflammatory effects in Crohn's disease depends upon viability and cytokine profile of the immune competent cells. J Physiol Pharmacol (2008) 59(1):177-87.

34. Lupke M, Frahm J, Lantow M, Maercker C, Remondini D, Bersani F, et al. Gene expression analysis of ELF-MF exposed human monocytes indicating the involvement of the alternative activation pathway. Biochim Biophys Acta (2006) 1763(4):402-12. doi:10.1016/j.bbamcr.2006.03.003

35. Noda Y, Mori A, Liburdy RP, Packer L. Magnetic fields and lipoic acid influence the respiratory burst in activated rat peritoneal neutrophils. Pathophysiology (2000) 7(2):137-41. doi:10.1016/S0928-4680(00)00041-9

36. Poniedzialek B, Rzymski P, Nawrocka-Bogusz H, Jaroszyk F, Wiktorowicz K. The effect of electromagnetic field on reactive oxygen species production in human neutrophils in vitro. Electromagn Biol Med (2013) 32(3):333-41. doi:10.3109/15368378.2012.721845

37. Reale M, De Lutiis MA, Patruno A, Speranza L, Felaco M, Grilli A, et al. Modulation of MCP-1 and iNOS by $50-\mathrm{Hz}$ sinusoidal electromagnetic field. Nitric Oxide (2006) 15(1):50-7. doi:10.1016/j.niox.2005.11.010

38. Rollwitz J, Lupke M, Simkó M. Fifty-hertz magnetic fields induce free radical formation in mouse bone marrow-derived promonocytes and macrophages. Biochim Biophys Acta (2004) 1674(3):231-8. doi:10.1016/j. bbagen.2004.06.024

39. Roy S, Noda Y, Eckert V, Traber MG, Mori A, Liburdy R, et al. The phorbol 12-myristate 13-acetate (PMA)-induced oxidative burst in rat peritoneal neutrophils is increased by a $0.1 \mathrm{mT}(60 \mathrm{~Hz})$ magnetic field. FEBS Lett (1995) 376(3):164-6. doi:10.1016/0014-5793(95)01266-X

40. Simkó M, Droste S, Kriehuber R, Weiss DG. Stimulation of phagocytosis and free radical production in murine macrophages by $50 \mathrm{~Hz}$ electromagnetic fields. Eur J Cell Biol (2001) 80(8):562-6. doi:10.1078/0171-9335-00187 
41. Varani K, Gessi S, Merighi S, Iannotta V, Cattabriga E, Spisani S, et al. Effect of low frequency electromagnetic fields on A2A adenosine receptors in human neutrophils. Br J Pharmacol (2002) 136(1):57-66. doi:10.1038/sj.bjp.0704695

42. Zmyslony M, Rajkowska E, Mamrot P, Politanski P, Jajte J. The effect of weak 50 $\mathrm{Hz}$ magnetic fields on the number of free oxygen radicals in rat lymphocytes in vitro. Bioelectromagnetics (2004) 25(8):607-12. doi:10.1002/bem.20045

43. Buldak RJ, Polaniak R, Buldak L, Zwirska-Korczala K, Skonieczna M, Monsiol A, et al. Short-term exposure to $50 \mathrm{~Hz}$ ELF-EMF alters the cisplatin-induced oxidative response in AT478 murine squamous cell carcinoma cells. Bioelectromagnetics (2012) 33(8):641-51. doi:10.1002/bem.21732

44. Eleuteri AM, Amici M, Bonfili L, Cecarini V, Cuccioloni M, Grimaldi S, et al. $50 \mathrm{~Hz}$ extremely low frequency electromagnetic fields enhance protein carbonyl groups content in cancer cells: effects on proteasomal systems. J Biomed Biotechnol (2009) 2009:834239. doi:10.1155/2009/834239

45. Falone S, Grossi MR, Cinque B, D’Angelo B, Tettamanti E, Cimini A, et al. Fifty hertz extremely low-frequency electromagnetic field causes changes in redox and differentiative status in neuroblastoma cells. Int J Biochem Cell Biol (2007) 39(11):2093-106. doi:10.1016/j.biocel.2007.06.001

46. Koh EK, Ryu BK, Jeong DY, Bang IS, Nam MH, Chae KS. A 60-Hz sinusoidal magnetic field induces apoptosis of prostate cancer cells through reactive oxygen species. Int J Radiat Biol (2008) 84(11):945-55. doi:10.1080/ 09553000802460206

47. Luukkonen J, Liimatainen A, Juutilainen J, Naarala J. Induction of genomic instability, oxidative processes, and mitochondrial activity by $50 \mathrm{~Hz}$ magnetic fields in human SH-SY5Y neuroblastoma cells. Mutat Res Fundam Mol Mech Mutagen (2014) 760:33-41. doi:10.1016/j.mrfmmm.2013.12.002

48. Morabito C, Guarnieri S, Fano G, Mariggio MA. Effects of acute and chronic low frequency electromagnetic field exposure on PC12 cells during neuronal differentiation. Cell Physiol Biochem (2011) 26(6):947-58. doi:10.1159/000324003

49. Morabito C, Rovetta F, Bizzarri M, Mazzoleni G, Fano G, Mariggio MA. Modulation of redox status and calcium handling by extremely low frequency electromagnetic fields in C2C12 muscle cells: a real-time, single-cell approach. Free Radic Biol Med (2010) 48(4):579-89. doi:10.1016/j.freeradbiomed.2009.12.005

50. Patruno A, Amerio P, Pesce M, Vianale G, Di Luzio S, Tulli A, et al. Extremely low frequency electromagnetic fields modulate expression of inducible nitric oxide synthase, endothelial nitric oxide synthase and cyclooxygenase- 2 in the human keratinocyte cell line HaCat: potential therapeutic effects in wound healing. $\mathrm{Br}$ J Dermatol (2010) 162(2):258-66. doi:10.1111/j.1365-2133.2009.09527.x

51. Polaniak R, Buldak RJ, Karon M, Birkner K, Kukla M, Zwirska-Korczala K, et al. Influence of an extremely low frequency magnetic field (ELF-EMF) on antioxidative vitamin E properties in AT478 murine squamous cell carcinoma culture in vitro. Int J Toxicol (2010) 29(2):221-30. doi:10.1177/1091581809352011

52. Vianale G, Reale M, Amerio P, Stefanachi M, Di Luzio S, Muraro R. Extremely low frequency electromagnetic field enhances human keratinocyte cell growth and decreases proinflammatory chemokine production. Br J Dermatol (2008) 158(6):1189-96. doi:10.1111/j.1365-2133.2008.08540.x

53. Wolf FI, Torsello A, Tedesco B, Fasanella S, Boninsegna A, D’Ascenzo M, et al. $50-\mathrm{Hz}$ extremely low frequency electromagnetic fields enhance cell proliferation and DNA damage: possible involvement of a redox mechanism. Biochim Biophys Acta (2005) 1743(1-2):120-9. doi:10.1016/j.bbamcr.2004.09.005

54. Zwirska-Korczala K, Adamczyk-Sowa M, Polaniak R, Sowa P, Birkner E, Drzazga $\mathrm{Z}$, et al. Influence of extremely-low-frequency magnetic field on antioxidative melatonin properties in AT478 murine squamous cell carcinoma culture. Biol Trace Elem Res (2004) 102(1-3):227-43. doi:10.1385/BTER:102:1-3:227
55. Zwirska-Korczala K, Jochem J, Adamczyk-Sowa M, Sowa P, Polaniak R, Birkner E, et al. Effect of extremely low frequency of electromagnetic fields on cell proliferation, antioxidative enzyme activities and lipid peroxidation in 3T3-L1 preadipocytes - an in vitro study. J Physiol Pharmacol (2005) 56(Suppl 6):101-8.

56. Park JE, Seo YK, Yoon HH, Kim CW, Park JK, Jeon S. Electromagnetic fields induce neural differentiation of human bone marrow derived mesenchymal stem cells via ROS mediated EGFR activation. Neurochem Int (2013) 62(4):418-24. doi:10.1016/j.neuint.2013.02.002

57. Droge W. Free radicals in the physiological control of cell function. Physiol Rev (2002) 82(1):47-95. doi:10.1152/physrev.00018.2001

58. Al-Gubory KH. Environmental pollutants and lifestyle factors induce oxidative stress and poor prenatal development. Reprod Biomed Online (2014) 29(1):17-31. doi:10.1016/j.rbmo.2014.03.002

59. Franco R, Sanchez-Olea R, Reyes-Reyes EM, Panayiotidis MI. Environmental toxicity, oxidative stress and apoptosis: menage a trois. Mutat Res (2009) 674(12):3-22. doi:10.1016/j.mrgentox.2008.11.012

60. Limon-Pacheco J, Gonsebatt ME. The role of antioxidants and antioxidantrelated enzymes in protective responses to environmentally induced oxidative stress. Mutat Res (2009) 674(1-2):137-47. doi:10.1016/j.mrgentox.2008.09.015

61. Hsieh HL, Yang CM. Role of redox signaling in neuroinflammation and neurodegenerative diseases. Biomed Res Int (2013) 2013:484613. doi:10.1155/2013/ 484613

62. Kim YW, Byzova TV. Oxidative stress in angiogenesis and vascular disease. Blood (2014) 123(5):625-31. doi:10.1182/blood-2013-09-512749

63. Selvaraju V, Joshi M, Suresh S, Sanchez JA, Maulik N, Maulik G. Diabetes, oxidative stress, molecular mechanism, and cardiovascular disease - an overview. Toxicol Mech Methods (2012) 22(5):330-5. doi:10.3109/15376516.2012.666648

64. Dizdaroglu M. Oxidatively induced DNA damage: mechanisms, repair and disease. Cancer Lett (2012) 327(1-2):26-47. doi:10.1016/j.canlet.2012.01.016

65. OECD. Guidance on Grouping of Chemicals, Second Edition. Environent, Health and Safety Publications. Series on Testing and Assessment No. 194. Paris: Organisation for Economic Co-operation and Development (2014). 141 p.

66. Vijayalaxmi, Prihoda TJ. Genetic damage in mammalian somatic cells exposed to extremely low frequency electro-magnetic fields: a meta-analysis of data from 87 publications (1990-2007). Int J Radiat Biol (2009) 85(3):196-213. doi:10.1080/09553000902748575

Conflict of Interest Statement: The authors declare that the research was conducted in the absence of any commercial or financial relationships that could be construed as a potential conflict of interest.

Received: 01 August 2014; paper pending published: 14 August 2014; accepted: 19 August 2014; published online: 02 September 2014

Citation: Mattsson M-O and Simkó M (2014) Grouping of experimental conditions as an approach to evaluate effects of extremely low-frequency magnetic fields on oxidative response in in vitro studies. Front. Public Health 2:132. doi: 10.3389/fpubh.2014.00132 This article was submitted to Radiation and Health, a section of the journal Frontiers in Public Health.

Copyright (C) 2014 Mattsson and Simkó. This is an open-access article distributed under the terms of the Creative Commons Attribution License (CC BY). The use, distribution or reproduction in other forums is permitted, provided the original author (s) or licensor are credited and that the original publication in this journal is cited, in accordance with accepted academic practice. No use, distribution or reproduction is permitted which does not comply with these terms. 